\title{
LTC Vacuum Blasting Machine (Metal) Baseline Report: Greenbook (Chapter)
}

\section{Topical Report July 31, 1997}

For

U.S. Department of Energy

Office of Environmental Management

Office of Technology Development

1000 Independence Avenue

Washington, DC 20585
U.S. Department of Energy

Office of Fossil Energy

Federal Energy Technology Center

Morgantown Site

P.O. Box 880

Morgantown, West Virginia 26507-0880

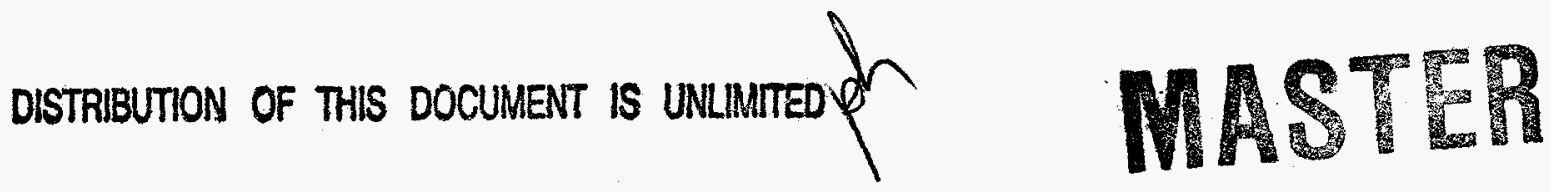

By

Operating Engineers National Hazmat Program

250 Airport Circle

Beaver, West Virginia 25813 


\section{Disclaimer}

This report was prepared as an account of work sponsored by an agency of the United States Government. Neither the United States Government nor any agency thereof, nor any of their employees, makes any warranty, express or implied, or assumes any legal liability or responsibility for the accuracy, completeness, or usefulness of any information, apparatus, product, or process disclosed, or represents that its use would not infringe privately owned rights. Reference herein to any specific commercial product, process, or service by trade name, trademark, manufacturer, or otherwise does not necessarily constitute or imply its endorsement, recommendation, or favoring by the United States Government or any agency thereof. The views and opinions of authors expressed herein do not necessarily state or reflect those of the United States Government or any agency thereof. 


\section{DISCLAIMER}

Portions of this document may be illegible electronic image products. Images are produced from the best available original document. 


\section{LTC VACUUM BLASTING MACHINE (METAL)}

\section{GREEN BOOK}

\section{TABLE OF CONTENTS}

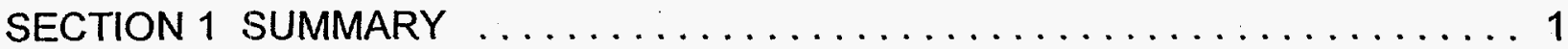

TECHNOLOGY DESCRIPTION $\ldots \ldots \ldots \ldots \ldots \ldots \ldots \ldots \ldots \ldots$

KEY RESULTS ...........................

SECTION 2 -TECHNOLOGY DESCRIPTION $\ldots \ldots \ldots \ldots \ldots \ldots \ldots \ldots \ldots 2$

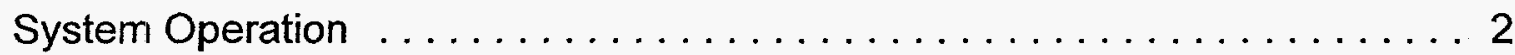

SECTION 3 - HEALTH AND SAFETY EVALUATION $\ldots \ldots \ldots \ldots \ldots \ldots \ldots \ldots$

General Health and Safety Concerns $\ldots \ldots \ldots \ldots \ldots \ldots \ldots \ldots \ldots$

Core issues . . . . . . . . . . . . . . . . . . . . . 3

Best Management Practices $\ldots \ldots \ldots \ldots \ldots \ldots \ldots \ldots \ldots \ldots \ldots \ldots \ldots \ldots$

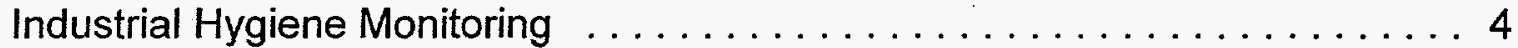

Human Factors Interface ........................ 6

Emergency Response/Preparedness $\ldots \ldots \ldots \ldots \ldots \ldots \ldots \ldots \ldots$

SECTION 4 - TECHNOLOGY APPLICABILITY $\ldots \ldots \ldots \ldots \ldots \ldots \ldots \ldots$

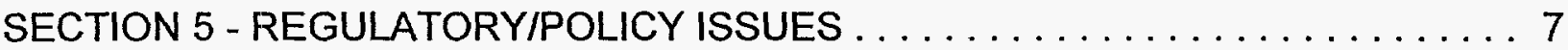

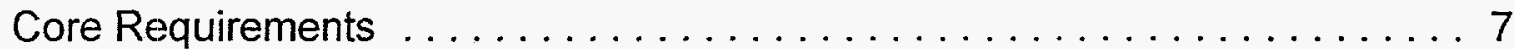

Special requirements $\ldots \ldots \ldots \ldots \ldots \ldots \ldots \ldots \ldots \ldots \ldots$

Best Management Requirements $\ldots \ldots \ldots \ldots \ldots \ldots \ldots \ldots \ldots \ldots . . .6$

Core Training Requirements . . . . . . . . . . . . . . . . . . . . 9

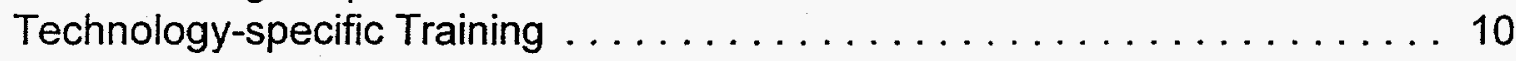

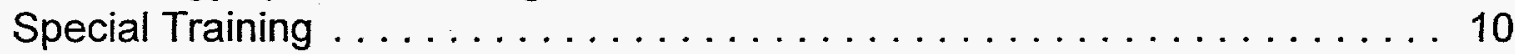

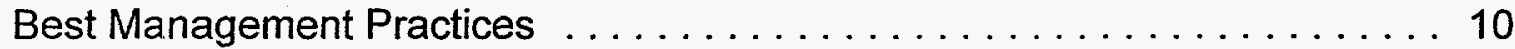

SECTION 6 - OPERATIONAL CONSIDERATIONS AND

RECOMMENDATIONS ....................... 11

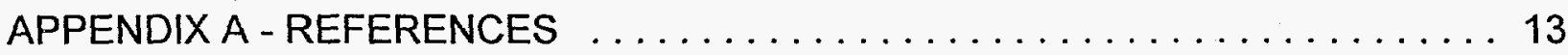

APPENDIX B - INDUSTRIAL HYGIENE DATA . . . . . . . . . . . . . 14 


\section{LTC AMERICAS, INC. \\ PTC-6 VACUUM SYSTEM (METAL) \\ HUMAN FACTORS EVALUATION}

\section{SECTION 1 - SUMMARY}

\section{TECHNOLOGY DESCRIPTION}

The LTC coating removal technology was tested and is being evaluated at Florida International University (FIU) as a baseline technology. In conjunction with FIU's evaluation of efficiency and cost, this report covers the evaluation conducted for safety and health issues. It is a commercially available technology and has been used for various projects at locations throughout the country.

The LTC coating removal system consisted of several hand tools, a Roto Peen scaler, and a needlegun. They are designed to remove coatings from steel, concrete, brick, and wood. These hand tools are used with the LTC PTC-6 vacuum system to capture dust and debris as removal of the coating takes place.

\section{KEY RESULTS}

The safety and health evaluation during the testing demonstration focused on two main areas of exposure: dust and noise. The dust exposure was minimal but noise exposure was significant. Further testing for each exposure is recommended because of the environment where the testing demonstration took place. It is feasible that the dust and noise levels will be higher in an enclosed operating environment of different construction. In addition, other areas of concern found were arm-hand vibration, wholebody vibration, ergonomics, heat stress, tripping hazards, electrical hazards, machine guarding, and lockout/tagout. 


\section{SECTION 2 \\ TECHNOLOGY DESCRIPTION}

\section{SYSTEM OPERATION}

The LTC coating removal technology was tested and is being evaluated at Florida International University (FIU) as a baseline technology. In conjunction with FIU's evaluation of efficiency and cost, this report covers the evaluation conducted for safety and health issues. It is a commercially available technology and has been used for various projects at locations throughout the country.

The LTC coating removal system consists of several hand tools, a Roto Peen scaler, and a needlegun. They are designed to remove coatings from steel, concrete, brick, and wood. These are used with the LTC PTC-6 vacuum system to capture dust and debris as removal of the coating takes place.

The PTC-6 is a vacuum system designed to be used with surface decontamination equipment. Dust and debris are captured by a high efficiency particulate air filter (HEPA) vacuum system that deposits the waste directly into an on-board 23-gallon waste drum. The PTC-6 utilizes compressed air delivered from a source via a hose connected to the air inlet to drive the hand held power tools. The air is delivered to the tools by air hoses which are attached to the control panel. The control panel regulates the air pressure delivered to the tool. A separate compressed air flow powers the vacuum generator. The vacuum hoses connect the power tools to the dust chamber, returning paint chips and dust from the surface. A third compressed air flow is used to clean filters by pulsing air through a pipe with slots. The blasts of air shake dust and debris from the filter fabric.

Due to problems associated with the operator's size and concern for his health, it was not possible to dress in PPE, other than gloves.

\section{SECTION 3 \\ HEALTH AND SAFETY EVALUATION GENERAL SAFETY AND HEALTH CONCERNS}

Personnel where the LTC descaling technology is being used need to be concerned with safety and health issues. Issues that personnel need to be cognizant of may be divided into two categories. First, core issues are those that are based on current safety and health regulatory requirements. Second, best management practices are related to issues that are not based on current safety and health regulations, but are key elements in preventing worker injury and illness on the job. Safety and health issues of concern with the LTC descaling technology included: 


\section{Core Issues:}

- Tripping hazards - although necessary, the electrical cords, air lines, and vacuum hoses needed to operate the equipment are tripping hazards. Therefore, the need for stringent housekeeping must be evaluated.

- Electrical hazards - electrical cords necessary to operate the equipment can present electrical hazards, therefore, the need for ground fault circuit interrupters, grounding, and strain relief must be evaluated.

- Lockout/Tagout - the user of the technology will need to develop a lockout/tagout program to assure there is not an accidental release of energy during maintenance/repair activities. One of the hand tools had a slide on/slide off switch which did not require the operator to maintain it in the on position. When the tool was lifted (upside down) from the surface, it continued to run. This has the potential to cause severe injury.

- Noise - the user was subjected to an extreme amount of noise while operating the hand tools used during the testing demonstration.

- Dust - the equipment generated some visible dust during operation, but dust was not evident in the breathing zone of the operator. Larger debris was left on the surface. The amount of dust generated in the breathing zone of the operator may change based on the environment in which the metal decontamination is taking place, therefore, the user of the technology will need to develop a sampling plan based on the individual site needs. It should also be noted that there was potential for contamination to dust when changing filters and during barrel change activities with the PTC-6.

\section{Best management practices:}

- Heat stress - the operator would potentially be subjected to an increase in heat stress due to the need to utilize PPE. The user will need to develop a heat stress program for the environment in which the technology is being used, taking into consideration any PPE that may need to be utilized.

- Ergonomics - the user was subjected to some ergonomic stressors that need to be taken into consideration, such as stooping, bending, twisting, kneeling, and lifting; and wrist, hand, arm, and shoulder stress and abnormal positioning. Of particular concern are the descalers which cause the wrist/arm/shoulder to be placed in awkward positions during operation. In addition, when full drums are being changed on the PTC-6, mechanical lifting devices need to be utilized. 
- Arm-hand vibration - the user was subjected to excessive arm-hand vibration during operation of the hand tools. This type of vibration has the potential to lead to health problems, such as Raynaud's Syndrome.

Whole-body vibration - the descaling operation caused vibration of the floor in the area. This potential for exposure to whole-body vibration will need to be assessed on a job-by-job basis based on the physical environment where the job is taking place.

- Struck by hazards - the air lines have the potential to cause severe injury if their fittings were to fail. A safety line between the male and female end of the fittings would prohibit the line from becoming airborne.

- Communication - due to the noise generated by the technology during operation, communication could be difficult. Personnel working in the area should be knowledgeable of and proficient in the use of hand signals when needed.

\section{Industrial Hygiene Monitoring}

During the testing demonstration with the PCT-6 descaling system, sampling was conducted for dust and noise. In addition, the wet-bulb globe temperature was monitored to evaluate heat stress. Observational evaluation was conducted for ergonomics and arm-hand vibration.

Through general observational techniques the potential for ergonomic problems was evaluated during the testing demonstration. There is potential for muscle/back stress and/or injuries due to bending, twisting, and lifting associated with setup, operation, maintenance, and decontamination. There is potential for stress on and/or injury to the knees due to the kneeling and stooping required during setup, maintenance, and decontamination activities. There is potential for wrist, hand, arm, and shoulder injury due to the awkward positions required during operation of the descalers. This was evident by the operator constantly changing hand position while using the equipment.

During the testing demonstration exposure to arm-hand vibration was present during the operation of the hand tools. While arm-hand vibration was not quantitatively measured, it was readily apparent that there was exposure that could potentially cause health problems, such as Raynaud's Syndrome. Whole-body vibration was also present during operation due to the vibration of the floor in the area.

Heat stress was monitored using a Quest QuestTemp ${ }^{\circ} 15$ Heat Stress Monitor. The wet-bulb globe temperature was used to determine the work/rest regimen in accordance with the American Conference of Governmental Industrial Hygienist (ACGIH) recommendations. The wet-bulb globe temperature was adjusted for the type of clothing, including PPE, that the worker was wearing. 
In addition, the worker's blood pressure, pulse, and temperature were monitored throughout the day. No problems were encountered due to heat stress. While heat stress will be increased while wearing PPE, the overall heat stress response will vary from worker to worker. Each situation in which the current technology is used will need to be evaluated for the heat stress potential, taking into consideration the wet-bulb globe temperature, PPE in use, physical condition of the worker, and amount of worker acclimatization.

Dust monitoring was conducted with a sampling train consisting of an SKC IOM Inhalable dust sampler coupled with an MSA Escort Elf air sampling pump. Pre- and post-sampling calibration was accomplished using a BIOS International DryCal DC1 primary calibration system. Sampling filters were desiccated pre- and post-sampling and weighed on a Denver Instrument Company A-200DS scale. Sampling was conducted in accordance with NIOSH method 0500.

Personal air sampling was conducted on the equipment operators during the descaling operation. Personal dust sampling results of $1.0417 \mathrm{mg} / \mathrm{m}^{3}$ were obtained for the operator. This value does not exceed the Occupational Safety and Health Administration (OSHA) permissible exposure limit (PEL) or the ACGIH threshold limit value (TLV) of $15 \mathrm{mg} / \mathrm{m}^{3}$ and $10 \mathrm{mg} / \mathrm{m}^{3}$ respectively for total dust. There was, however, larger pieces of debris left on the surfaces being descaled. This debris could potentially become airborne and, therefore, become an inhalation hazard. Due to this and the dust sampling being conducted in a room with open windows, it is recommended that sampling be conducted while the descaling operation is being carried out in a closed environment. A complete air sampling plan for a site would need to be developed to include not only dust but other contaminants specific to the metal decontamination project. (See Appendix B for sampling data.)

Personal noise monitoring was conducted using a Metrosonic $\mathrm{db}-3100$ data logging noise dosimeter. Calibration was conducted pre- and post-monitoring using a Metrosonics CL304 acoustical calibrator. Monitoring was conducted on the operator for 1.35 hours ( 81 minutes), and 4.45 hours ( 267 minutes) during operation of the descaling technology. Monitoring during this time showed a noise dose of $810.69 \%$ which gives an 8-hour time-weighted average (TWA) of $105.1 \mathrm{dBA}$, and $1871.96 \%$ which gives an 8-hour TWA of $111.1 \mathrm{dBA}$. If the operator continued to have the same level of noise exposure during the 8-hour shift a projected 8-hour TWA would produce a noise dose of $8023.32 \%$ or an 8-hour TWA of $121.6 \mathrm{dBA}$, and $4307.78 \%$ or an 8 -hour TWA of $112.1 \mathrm{dBA}$.

The OSHA allowable PEL for noise is a $100 \%$ dose or an 8 -hour TWA of $90 \mathrm{dBA}$. The operator was overexposed after all periods of time. At these exposure levels, personnel would be required to be included in a hearing conservation program. Feasible engineering controls, administrative controls, and personal protective equipment (PPEhearing protection devices) need to be used. Taking the highest projected 8-hour exposure TWA, which was $121.6 \mathrm{dBA}$, and assuming the use of a hearing protection 
device with the highest noise reduction rating (per the NIOSH Compendium of hearing protection devices) was being used, the worker would theoretically still be overexposed for an 8-hour shift. The excessive noise levels produced by the descaling operation may require that engineering and administrative controls, as well as hearing protection devices, all be simultaneously employed to control the noise level. The percentage of time spent at each loudness level that comprises the exposures can be seen in Appendix B.

During the different periods of operation for the operator, the noise levels were averaged for each one minute period of time and then an overall average was calculated which gave an average exposure level of $121.6 \mathrm{dBA}$ for an $80 \mathrm{~dB}$ and $90 \mathrm{~dB}$ cutoff level, and $117.1 \mathrm{~dB}$ for an $80 \mathrm{~dB}$ and a $90 \mathrm{~dB}$ cutoff level. OSHA requires an 80 $\mathrm{dB}$ cutoff for hearing conservation measurements and a $90 \mathrm{~dB}$ cutoff for engineering controls compliance measurements. The maximum sound level observed during the measurement periods was $131.7 \mathrm{dBA}$. The highest instantaneous sound pressure level was over $140 \mathrm{~dB}$.

These measurements define noise as an extreme exposure hazard for personnel operating the LTC descaling technology. It must also be noted that the equipment was being operated in a wooden walled and floored structure at the time of the measurements and operation in a facility of different construction will have the potential to increase the noise level due to other influences such as vibration and reverberation. Therefore, it is recommended that noise monitoring be conducted while the equipment is being operated in environments of differing types of construction.

\section{HUMAN FACTORS INTERFACE}

Due to problems associated with the operator's size and concern for his health, he could not be dressed out in PPE. The need to utilize Level C PPE which may include a Tyvek suit with hood, work gloves, boot coverings, and full face air-purifying respirator needs to be taken into consideration when assessing worker safety and health. Areas of concern include visibility, dexterity, and heat stress.

If the metal being decontaminated had contamination other than or in addition to dust, additional levels of protection, such as Level A or Level B PPE, may be required for the operator. These may create additional human interface problems such as a greater decrease in visibility and manual dexterity, an increase in heat stress, and an overall increase in physical stress. It is recommended that additional safety and health evaluations be conducted utilizing these higher levels of protection.

Additional human factors interface issues included the amount of arm-hand vibration the operator was receiving during operation of the hand tools. It is recommend that 
further evaluation with quantitative measurements of arm-hand vibration be conducted for this equipment.

\section{EMERGENCY RESPONSE/PREPAREDNESS}

The use of the LTC metal descaling technology would not be applicable to emergency response.

Emergency response/preparedness must be part of every hazardous waste site safety and health plan. In addition to credible site emergencies, site personnel must plan for credible emergencies in connection with the LTC metal descaling system.

All precautions used when responding to an emergency situation at the site will apply. Before entering an area where the LTC- 6 vacuum system is being used, the equipment needs to be completely shut down (de-energized).

This technology does not appear to present any conditions that would lead to out of the ordinary emergencies.

\section{SECTION 4 TECHNOLOGY APPLICABILITY}

On observation the technology did not generate visible dust and air monitoring did not show a significant dust level, but this was difficult to assess due to the open windows in the testing environment. There were larger pieces of debris left on the surface during descaling. The system needs to be evaluated to determine if an increase in vacuum air flow would help with this problem.

The hand tools and PTC-6 vacuum system will need to be torn down to decontaminate them. This will not necessarily guarantee that decontamination will be complete.

Many parts, such as the hoses, roto peens, and needles may need to be considered consumables.

\section{SECTION 5 REGULATORYIPOLICY ISSUES}

The site safety and health personnel where the LTC metal descaling technology is being used need to be concerned with safety and health regulations applicable to the issues discussed above. Regulations that apply may be divided into four categories. First, core requirements are those regulations that would apply to any hazardous waste work site, regardless of the type of job. Second, technology-specific requirements are those regulations that apply due to the specific technology being used. Third, special 
requirements are standards and policies that are specific to the technology itself, but are required by reference in a regulation. Fourth, best management practices are not required but are recommended by organizations such as the American National Standards Institute (ANSI), the National Institute of Occupational Safety and Health (NIOSH), Department of Energy (DOE), National Fire Protection Association (NFPA), etc. These regulations/standards may include, but not be limited to, the following:

\section{Core requirements:}

- OSHA 29 CFR 1926.25 Housekeeping

OSHA 29 CFR 1910.141 Sanitation (1910.141(a)(3) covers housekeeping)

- OSHA 29 CFR 1926 Subpart Z Toxic and Hazardous Substances

OSHA 29 CFR 1910 Subpart Z Toxic and Hazardous Substances

$-\quad$ OSHA 29 CFR 1926.59 Hazard Communication

- OSHA 29 CFR 1910.1200 Hazard Communication

OSHA 29 CFR 1926.64 Process Safety Management of Highly Hazardous Chemicals

OSHA 29 CFR 1910.119 Process Safety Management of Highly Hazardous Chemicals

- OSHA 29 CFR 1926.65 Hazardous Waste Operations and Emergency Response

OSHA 29 CFR 1910.120 Hazardous Waste Operations and Emergency Response

- Occupational Safety and Health Act 1970(5)(a)(1) General Duty Clause

Technology specific requirements:

- OSHA 29 CFR 1926 Subpart K Electrical

- OSHA 29 CFR 1910 Subpart S Electrical

OSHA 29 CFR 1926 Subpart I Tools-Hand and Power 
- OSHA 29 CFR 1910 Subpart P Hand and Portable Powered Tools and Other Hand-Held Equipment

- OSHA 29 CFR 1910 Subpart O Machinery and Machine Guarding

- OSHA 29 CFR 1910.147 The Control of Hazardous Energy (Lockout/Tagout)

- OSHA 29 CFR 1926.52 Occupational Noise Exposure

- OSHA 29 CFR 1910.95 Occupational Noise Exposure

- OSHA 29 CFR 1926.103 Respiratory Protection

- OSHA 29 CFR 1910.134 Respiratory Protection

- OSHA 29 CFR 1926.102 Eye and Face Protection

$-\quad$ OSHA 29 CFR 1910.133 Eye and Face Protection

- OSHA 29 CFR 1926.28 Personal Protective Equipment

OSHA 29 CFR 1910.132 Personal Protective Equipment

- OSHA 29 CFR 1910.132 General Requirements (Personal Protective Equipment)

- OSHA 29 CFR 1926.23 First Aid and Medical Attention

$-\quad$ OSHA 29 CFR 1910.151 Medical Services and First Aid

- ACGIH Threshold Limit Values for Chemical Substances and Physical Agents and Biological Exposure Indices

Best management practices:

- ANSI S3.34-1986 Guide for the Measurement and Evaluation of Human Exposure to Vibration Transmitted to the Hand

- ANSI S3.18-1979 Guide for the Evaluation of Human Exposure to Whole-body Vibration

In addition to the above regulations and policies, it is imperative that all workers have appropriate and adequate training for the task and associated safety and health conditions. Training that would be required may be divided into four categories. Core training is that which is required for anyone entering a hazardous waste site to perform 
work, regardless of the type of job. Technology specific training is that training that is specific to the technology and required by safety and health standards. Special training is that which is specific to the technology to assure the worker is adequately trained for the task but is not necessarily required by safety and health standards. Best management practices are trainings that while not mandated by health and safety standards, provide information and knowledge to the worker that will allow the worker to perform the job safely. Training to be applied for the heavy duty roto peen may include but not be limited to:

Core training requirements:

HAZWOPER (Hazardous Waste Operations and Emergency Response)

- HAZCOM (Hazard Communication)

Special training:

- Job specific training for equipment operation

Best Management Practice training:

Ergonomics (proper lifting, bending, stooping, kneeling, arm-hand vibration, whole-body vibration)

- Heat stress (learning to recognize signs and symptoms)

- CPR/First Aid/Emergency Response/Bloodborne Pathogens

- Hand Signal Communication

- Construction Safety (OSHA 500) and or General Industry Safety (OSHA 501) 


\section{SECTION 6 OPERATIONAL CONSIDERATIONS \& RECOMMENDATIONS}

Recommendations made in this section for improved worker safety and health take into consideration the operation of hand tools with the LTC PTC- 6 vacuum system. Specific recommendations include:

- It needs to be assured that workers are aware of the tripping hazards associated with hoses and cords that are necessary to operate the equipment. Keeping these as orderly as possible in compliance with good housekeeping regulations will help avoid injury due to tripping.

- The vacuum hoses were not connected to the outlet on the pieces of equipment by means of a clamping system. This could allow the hoses to be pulled loose and create an exposure to the contaminant. Hoses should be attached with some type of clamping system to reduce the possibility that they will become detached accidentally.

- The operators of the equipment need to have training in ergonomics to assure proper techniques in lifting, bending, stooping, twisting, etc. during equipment operation. In addition, training needs to include discussion on ergonomics associated with the wrists/hands, arms, and shoulders when using hand tools. The tools themselves need to be evaluated for ergonomic design to enable the worker to use them without having to place themselves in awkward positions. For example, the workers had to place his hands on the housing of the one hand tool to move and control it because there was no handle. A better design to include a handle would allow the worker to move it to the required position. The lack of a handle also increased the worker's exposure to arm/hand vibration.

- If a fitting on an air line fails, the flying hose has the potential to cause severe injury. A safety line connected to the male and female parts of the fitting would not allow the hose to become a flying object.

- A full 23-gallon drum may weigh 220 pounds or more and a 55-gallon even more. This presents great potential for back injury when two operators lift the drum for change out. It is recommended that the system be evaluated for use with a mechanical lifting system.

- The cleaning (blow back) of the filters was a manual operation. If this were automated to occur at set intervals of time, the operation would be more efficient. 
- Noise exposure was extreme during operation of the technology. Since testing was done in a wooden structure, it is plausible that the noise levels would increase in an environment of different construction. The equipment needs to be evaluated for possible engineering controls to help decrease the noise exposure to the operator. If engineering controls are not possible, administrative controls, and/or adequate hearing protection must be incorporated during operation.

- The one hand tool had a push on/push off control switch that did not require the operator to maintain contact with the switch during operation. When the tool was lifted from the surface, it continued to run. This presents a potential for the operator to come in contact with moving parts as well as increasing the potential for exposure to the contaminant. The tool design needs to be evaluated for the use of an interlock system which stops the tool if it loses contact with the surface.

- The hand tools were being used inside a shed constructed for the purposes of the testing demonstration. The PTC- 6 vacuum system was located outside of the shed. The operator started the vacuum system and a hand tool that was in the on position. It became energized but no one had control of it. This could lead to damage to the facility, electric cords, vacuum hoses or other personnel inside the building. The operator should ensure that all hand tools are off before starting the system.

Due to the open window environment in which the testing demonstration was conducted and, therefore, the dust monitoring was conducted, it is recommended that further testing for dust exposure be conducted while the technology is used in a closed environment similar to environments in which it would be used at a hazardous waste clean-up site. Due to the wooden structure in which the testing demonstration took place, and therefore, the noise monitoring was conducted, it is recommended that noise monitoring be conducted while the technology is used inside an environment of different construction. There could be a difference in noise levels due to the construction of the building. This would also allow for an evaluation of the heat stress to be encountered while wearing the appropriate PPE in different environments. In this case, Level C needs to also be evaluated.

It is also recommended that the operation and maintenance activities be evaluated while the operator is wearing Level A and Level B PPE since these levels may be needed in environments where the contamination requires it.

The safety and health issues discussed throughout this report could be reduced and, in some cases, eliminated if this type of descaling technology could operate remotely. 


\section{APPENDIX A \\ REFERENCES}

Occupational Safety and Health Standards for General Industry, 29 CFR Part 1910, Occupational Safety and Health Administration United States Department of Labor, 1995

Occupational Safety and Health Standards for the Construction Industry, 29 CFR Part 1926, Occupational Safety and Health Administration United States Department of Labor, 1995

Threshold Limit Values (TLVs) for Chemical Substances and Physical Agents and Biological Exposure Indices (BEls), American Conference of Governmental Industrial Hygienists, 1995-1996

ANSI 1986, Guide for the measurement and evaluation of human exposure to vibration transmitted to the hand, New York, NY: American National Standards Institute, ANSI S3.34

The NIOSH compendium of hearing protection devices, U.S. Department of Health and Human Services, Public Health Service, Center for Disease Control and Prevention, October 1994 
APPENDIX B

IH SAMPLING DATA

\begin{tabular}{|c|c|c|c|}
\hline \multicolumn{4}{|c|}{$\begin{array}{l}\text { Pentek ROTOPEEN Scaler. CORNER CUTIIER } \\
\text { Total Bust Sampling }\end{array}$} \\
\hline rate & 5.1178) & añale & 8.89 .8118 \\
\hline $5 / 29 / 96$ & 052996-FIU-022 & Blank & $0.0000 \mathrm{mg} / \mathrm{m}^{3}$ \\
\hline $5 / 29 / 96$ & 052996-FIU-023 & Total dust & $1.0417 \mathrm{mg} / \mathrm{m}^{3}$ \\
\hline
\end{tabular}

* The OSHA PEL for total dust is $15 \mathrm{mg} / \mathrm{m}^{3}$ and the ACGIH TLV is $10 \mathrm{mg} / \mathrm{m}^{3}$. Current sampling was conducted for total dust. The need to sample for respirable dust and silica has to be considered during concrete decontamination and decommissioning activities. 


\section{NOISE SAMPLING}

Amplitude pistribution pata

(⿸丆口

19.0

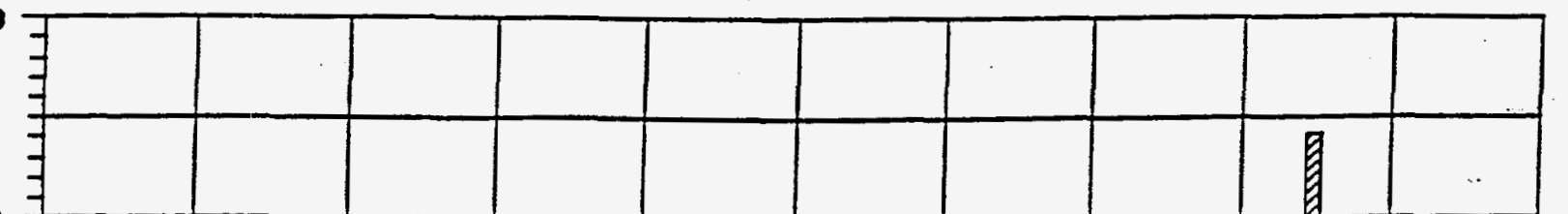

6.0

8.8

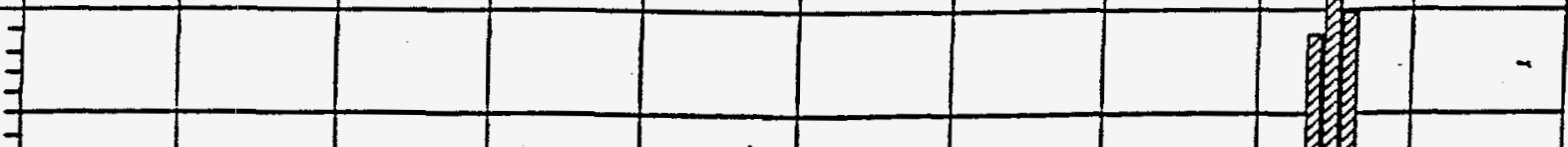

4.8

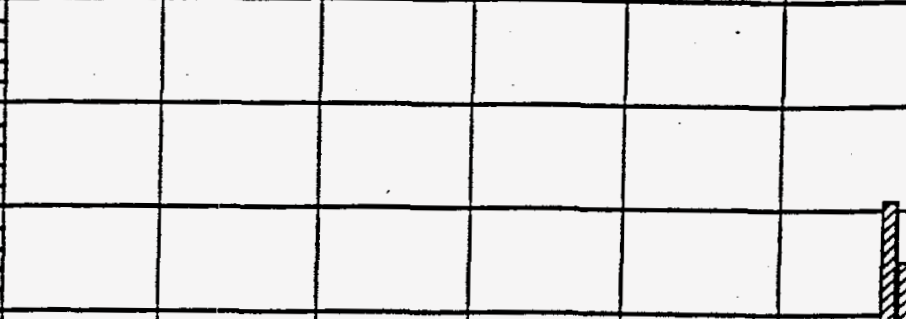

2.8
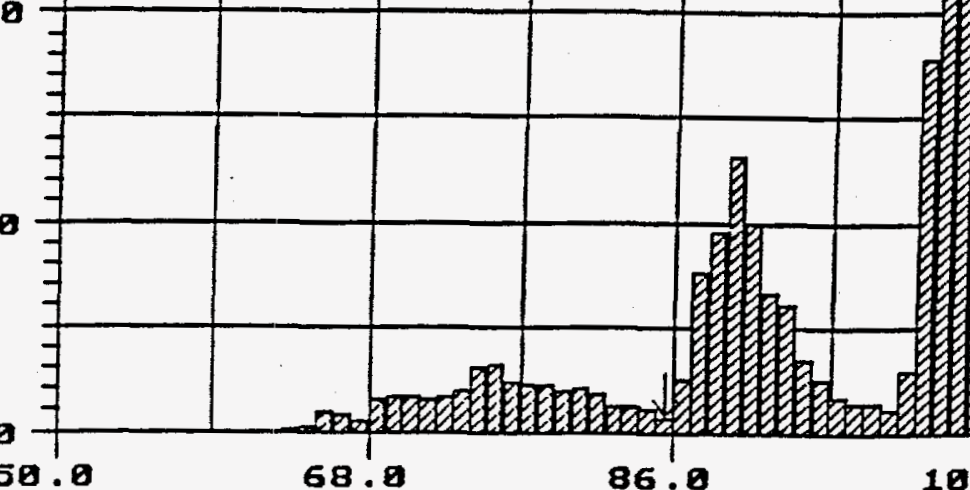

50.8

68.9

86.0

122.8

49.6

QS5.0dB : $7.012 \%$

$85.8 \rightarrow 85.9 d B$ :

B. $135 \%$

$\operatorname{Ln}(92.852)=85.9 d B$

The percentage of time spent at each decibel Level $C$ can be obtained from the graph. As shown, $7.012 \%$ of the time the noise exposure was less than $85 \mathrm{dBA}$ which means that the majority of the time or $92.98 \%$ of the time the noise exposure was at sound levels above $85 \mathrm{dBA}$. OSHA requires that a hearing conservation program be initiated if the 8-hour TWA is $85 \mathrm{dBA}$. 


\section{NOISE SAMPLING}

Amplitude Distribution pata

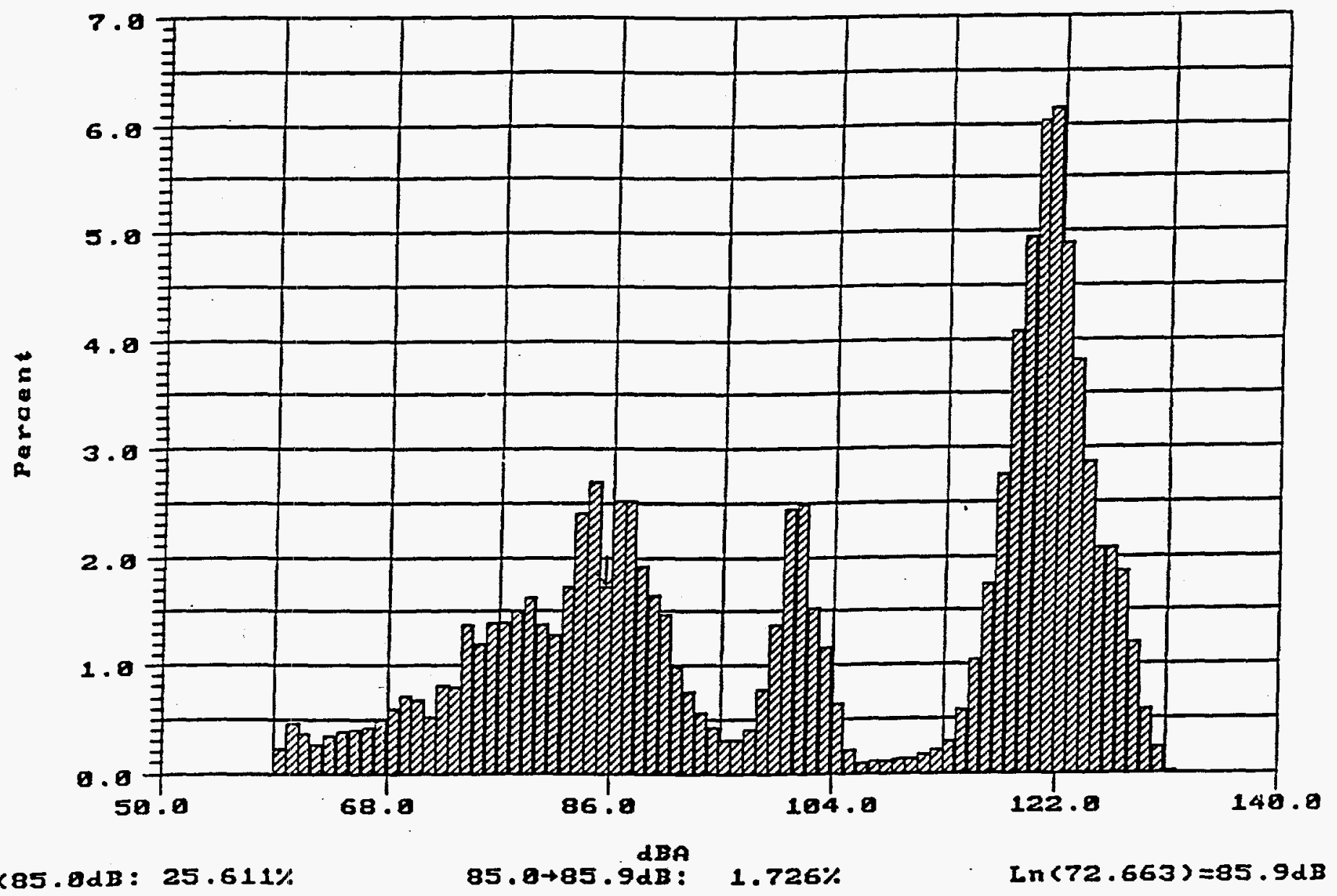

The percentage of time spent at each decibel Level $C$ can be obtained from the graph. As shown, $25.611 \%$ of the time the noise exposure was less than $85 \mathrm{dBA}$ which means that the majority of the time or $74.389 \%$ if the time the noise exposure was at sound levels above $85 \mathrm{dBA}$. OSHA requires that a hearing conservation program be initiated if the 8-hour TWA is $85 \mathrm{dBA}$. 